\title{
Differential Pulse Voltammetric Determination of Fulvestrant in Pharmaceutical Dosage Forms and Serum Samples
}

\author{
Dilek Kul,, ${ }^{1}$ Burcu Doğan-Topal, ${ }^{2}$ Sibel A. Özkan,, ${ }^{2}$ and Bengi Uslu² \\ ${ }^{1}$ Faculty of Pharmacy, Karadeniz Technical University, 61080 Trabzon, Turkey \\ ${ }^{2}$ Department of Analytical Chemistry, Faculty of Pharmacy, Ankara University, Tandogan, 06100 Ankara, Turkey \\ Correspondence should be addressed to Bengi Uslu, buslu@pharmacy.ankara.edu.tr
}

Received 9 November 2010; Accepted 3 December 2010

Academic Editor: Hassan Y. Aboul-Enein

Copyright ( $\odot 2011$ Dilek Kul et al. This is an open access article distributed under the Creative Commons Attribution License, which permits unrestricted use, distribution, and reproduction in any medium, provided the original work is properly cited.

\begin{abstract}
The electrooxidation behavior and determination of fulvestrant at a glassy carbon electrode were investigated. The voltammetric study of the model compounds allowed elucidating the possible oxidation mechanism of fulvestrant. The dependence of the peak current and peak potentials on $\mathrm{pH}$, concentration, nature of the buffer, and scan rate was determined. The oxidation of fulvestrant showed a single and irreversible peak at glassy carbon electrode, and the process was found diffusion controlled. Linear responses were obtained for the concentrations between $4 \times 10^{-6} \mathrm{M}$ and $6 \times 10^{-5} \mathrm{M}$ in standard samples and between $2 \times 10^{-5} \mathrm{M}$ and $1 \times 10^{-4} \mathrm{M}$ in serum samples. The repeatability of the method was found $0.93 \mathrm{RSD} \%$. The repeatability, reproducibility, precision, and accuracy of proposed method were investigated.
\end{abstract}

\section{Introduction}

Fulvestrant is a member of a group of drugs called estrogen receptor downregulators. Most breast cancer cells have estrogen receptors on their cell surface. Estrogen stimulates these cells with estrogen receptors to divide without regard to the body's estrogen needs. This is referred to as "estrogenreceptor-positive breast cancer." Fulvestrant works by blocking and destroying the estrogen receptor in the cell so that estrogen cannot bind to it. The action effectively lowers (downregulates) the estrogen receptor activity in the cell so that it acts more like a normal cell $[1,2]$.

Fulvestrant has a steroidal structure 7-alpha-(9-((4,4,5,5, 5-pentafluoropentyl) sulfinyl) nonyl) estra-1,3,5(10)-triene, 3,7 beta-diol) (Scheme 1), which when complexed with oestrogen receptors prevents its dimerisation and renders the receptor transcriptionally inactive [3-6].

There has been no study published on quantitative determination of fulvestrant in pharmaceutical formulations. Moreover, no monograph of fulvestrant has been reported in the official pharmacopoeias as of today.

The widespread use of this compound and the need for clinical and pharmacological studies require fast and sensi- tive analytical techniques to assay the drug in pharmaceutical dosage forms and biological samples. These may also be used for monitoring patient compliance and establishing relationship between blood concentration and the therapeutic effects, which are not always fully understood.

In the last decades, modern-computer-based voltammetric techniques have been used to realize the determination of organic chemicals in diverse types of samples, especially pharmaceutical fields. The advance in experimental electrochemical techniques in the field of drug analysis is because of their straightforwardness, low cost, and relatively short analysis times no need for derivatizations or timeconsuming extraction steps when compared with other analytical techniques [7-12]. Cyclic voltammetry (CV) is the most widely used technique for qualitative information about electrochemical reactions. Conventionally, glassy carbon (GC) is widely used for working electrodes especially for analytical applications because of its relatively wide potential window in comparison with metal electrodes such as $\mathrm{Au}$ and Pt. GC is composed almost exclusively of $\mathrm{sp}^{2}$-type carbon. The electronic and electrochemical properties of this electrode depend on several factors including surface preparation, microstructure, and presence of carbon-oxygen functional groups. 


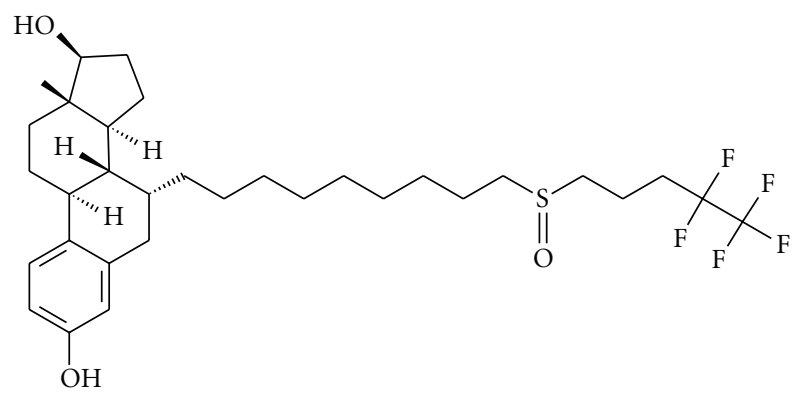

Scheme 1: Chemical formula of fulvestrant.

This work is aimed to study the detailed voltammetric oxidation mechanism of fulvestrant at GC electrode using $\mathrm{CV}$. Also, the proposed method has been applied to the determination of electroactive fulvestrant and quantitation of fulvestrant in pharmaceutical dosage form, and human serum samples using differential pulse voltammetry (DPV).

\section{Experimental}

2.1. Equipment. Voltammetric experiments were performed using a BAS $100 \mathrm{~W}$ (Bionalytical System, USA) electrochemical analyzer associated to one-compartment glass electrochemical cell equipped with a three-electrode system consisting of a glassy carbon (GC) electrode (BAS; $3 \mathrm{~mm}$, diameter), working electrode, a platinum wire counter electrode and an $\mathrm{Ag} / \mathrm{AgCl}$ saturated $\mathrm{KCl}$ reference electrode. GC electrode was polished manually with aqueous slurry of alumina powder $(0.01 \mu \mathrm{m}$, diameter $)$ on a damp smooth polishing cloth (BAS velvet polishing pad) before each experiment.

The $\mathrm{pH}$ measurements were completed using a model 538, WTW pH-meter (Austria) with a combined electrode (Glass-reference electrodes) with an accuracy of $\mathrm{pH} \pm 0.05$.

The experimental conditions for differential pulse voltammetry (DPV) were as follows: pulse amplitude of $50 \mathrm{mV}$, pulse width of $50 \mathrm{~ms}$, and scan rate of $20 \mathrm{mV} / \mathrm{s}$.

2.2. Reagents. Fulvestrant and its pharmaceutical dosage form were kindly supplied by Astra Zeneca (Istanbul, Turkey). Model compounds, levodopa, carbidopa, benserazide, epirubicin, and doxorubicin were kindly supplied from different pharmaceutical companies in Turkey. Other chemicals were reagent grade (Merck or Sigma).

Stock solutions of fulvestrant $\left(1 \times 10^{-3} \mathrm{M}\right)$ were prepared in acetonitrile and kept in the dark at $4^{\circ} \mathrm{C}$. Fulvestrant working solutions for voltammetric investigations were prepared by dilution of the stock and contained 30\% acetonitrile. Four different supporting electrolytes, sulphuric acid solution $(0.1 \mathrm{M}$ and $0.5 \mathrm{M})$, phosphate buffer $\left(0.2 \mathrm{M} \mathrm{H}_{3} \mathrm{PO}_{4} ; 0.2 \mathrm{M}\right.$ $\mathrm{NaH}_{2} \mathrm{PO}_{4} \cdot 2 \mathrm{H}_{2} \mathrm{O} ; 0.2 \mathrm{M} \mathrm{Na}_{2} \mathrm{HPO}_{4} ; \mathrm{pH}$ 2.0-8.0), BrittonRobinson buffer $\left(0.04 \mathrm{M} \mathrm{H}_{3} \mathrm{BO}_{3} ; 0.04 \mathrm{M} \mathrm{H}_{3} \mathrm{PO}_{4}\right.$, and $0.04 \mathrm{M} \mathrm{CH}_{3} \mathrm{COOH}$; pH 2.0-10.0), and acetate buffer $(0.2 \mathrm{M}$ $\mathrm{CH}_{3} \mathrm{COOH} ; \mathrm{pH}$ 3.5-5.5), were used for electrochemical measurements. All the solutions were protected from light and were used within $24 \mathrm{~h}$ to avoid decomposition. All measurements were carried out at the ambient temperature of the laboratory $\left(23-27^{\circ} \mathrm{C}\right)$. The calibration curve for DPV analysis was constructed by plotting the peak current versus the fulvestrant concentration.

The ruggedness and precision were checked at different days. The results were given as repeatability (within day) and reproducibility (between days). Relative standard deviations (RSDs) were calculated to check the ruggedness and precision of the method $[9,13-19]$.

The accuracy and precision of the developed methods are described in a quantitative fashion by the use of relative errors (Bias\%). An example of the Bias\% is the accuracy which describes the deviation from the expected results.

2.3. Injectable Solution Assay. $1.21 \mathrm{~mL}$ of Faslodex injectable solution, maintain to contain $250 \mathrm{mg}$ fulvestrant per $5 \mathrm{~mL}$ of the solution, was dissolved in $100 \mathrm{~mL}$ of acetonitrile. An aliquot of this solution was transferred into a $10.0 \mathrm{~mL}$ volumetric flask and diluted to the mark with supporting electrolyte, and the voltammogram was recorded.

The nominal content of the injectable solution was determined from corresponding regression equation.

2.4. Analysis of Serum. Drug-free human blood, obtained from healthy volunteers (after obtaining their signed consent), was centrifuged $(5000 \mathrm{rpm})$ for $30 \mathrm{~min}$ at room temperature. The separated serum samples were stored frozen until assay. An aliquot volume of the serum sample was fortified with fulvestrant dissolved in acetonitrile to achieve final concentration of $1 \times 10^{-3} \mathrm{M}$. This solution contained acetonitrile as serum precipitating agent. Acetonitrile removed serum proteins effectively, by the addition of 1 volume to 1.5 volumes of the serum. The mixture was vortexed for $30 \mathrm{~s}$ and centrifuged for $10 \mathrm{~min}$ at $5000 \mathrm{rpm}$ to remove serum protein residues, and the supernatant was taken carefully. Appropriate volumes of the supernatant were transferred to the volumetric flask and diluted to the chosen volumes with $0.1 \mathrm{M}$ sulphuric acid solution. The concentration of fulvestrant in the prepared solutions was varied in the range of $2 \times 10^{-5} \mathrm{M}-1 \times 10^{-4} \mathrm{M}$ using DPV technique with GC electrode in human serum samples.

Quantifications were performed by means of the calibration curve method from the related calibration equation.

\section{Results and Discussion}

The electrochemical behavior of fulvestrant on the glassy carbon electrode was studied by CV, linear sweep voltammetry (LSV), and differential pulse voltammetry (DPV). Various supporting electrolytes were investigated using CV: phosphate buffer, Britton-Robinson buffer, acetate buffer, and sulphuric acid. The best result was obtained with $0.1 \mathrm{M}$ sulphuric acid; peak oxidation potential $0.83 \mathrm{~V}$ versus $\mathrm{Ag} / \mathrm{AgCl}\left(3.0 \mathrm{molL}^{-1} \mathrm{KCl}\right)$ was obtained for fulvestrant (Figure 1). 


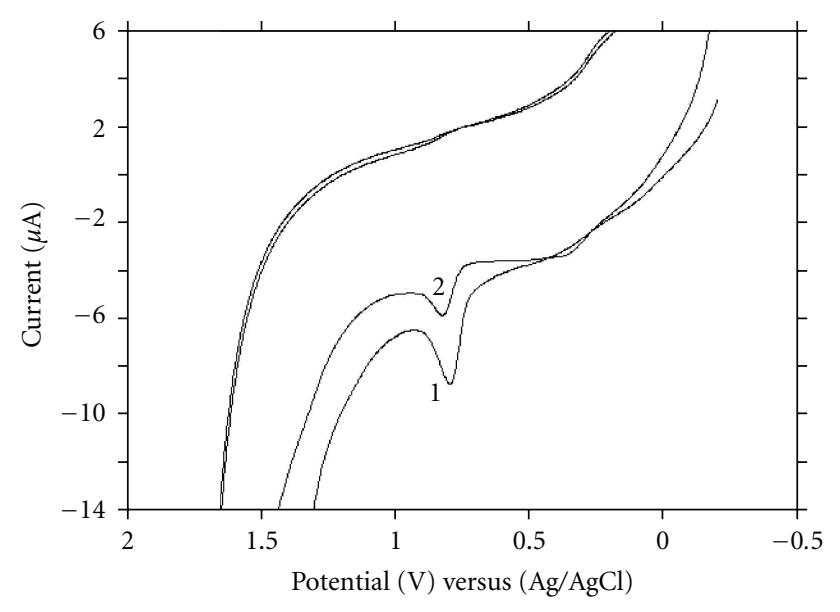

Figure 1: (1) First cycle and (2) second cycle of the repetitive voltammograms for $8 \times 10^{-5} \mathrm{M}$ fulvestrant solution in $0.1 \mathrm{M}$ sulphuric acid solution. Curves are from 0 to $+1.8 \mathrm{~V}$. Scan rate is $100 \mathrm{mV} / \mathrm{s}$.

Voltammogram obtained for fulvestrant at the GC electrode presented an irreversible chemical behavior in all supporting electrolytes. Cyclic voltammogram of $8 \times 10^{-5} \mathrm{M}$ fulvestrant using GC electrode (sweep rate $100 \mathrm{mV} / \mathrm{s}$ ) exhibited a single well-defined and irreversible oxidation peak at $0.83 \mathrm{~V}$. No peaks were observed on the reverse scan corresponding to the main anodic peak. This observation confirmed the irreversibility of the oxidation process (Figure 2).

The plot of the peak potential (Ep) versus $\mathrm{pH}$ created a straight line (Figure 3(a)) between $\mathrm{pH} 1.0$ and 10.0. The peak potential moved to less positive values by increasing the $\mathrm{pH}$. This can be expressed by the following equation:

$\mathrm{Ep}=784.05-55.81 \mathrm{pH} ; r=0.994$.

(SE of intercept: $1.17 \times 10^{1}$, SE of slope: 1.84 )

(Acetate, phosphate, and BR buffer between $\mathrm{pH} 1.0$ and 10.0).

The intersection of the curves was located around $\mathrm{pH}$ 10.0 for GC electrode. This value was found similar to the value given in the literature which is 10.03 [20]. The peak potential seemed to be $\mathrm{pH}$ independent after a $\mathrm{pH}$ value of 10.0 .

The effect of $\mathrm{pH}$ (within the range of 1.8-12.0) on the peak current of fulvestrant was investigated (Figure 3(b)). The plot of $I_{p}$ versus $\mathrm{pH}$ indicated that the peak current reached a maximum for $0.1 \mathrm{M} \mathrm{H}_{2} \mathrm{SO}_{4}$. Therefore, $0.1 \mathrm{M}$ $\mathrm{H}_{2} \mathrm{SO}_{4}$ was chosen as the supporting electrolyte for the quantitative determination part of the study. This supporting electrolyte showed sharp response and better peak shape for the calibration equation of pharmaceutical dosage forms and biological samples.

The peak potential shifted to more positive potentials (about $66 \mathrm{mV}$ ) to the anodic direction when the scan rate was increased for GC electrode which can be expressed by the following equation:

$$
\begin{aligned}
& \mathrm{Ep}(\mathrm{mV})=0.34 v(\mathrm{mV} / \mathrm{s})+764.13 ; r=0.976, \\
& n=6(\text { for } 5-100 \mathrm{mV} / \mathrm{s})
\end{aligned}
$$

(SE of intercept: 2.11, SE of slope: $3.77 \times 10^{-2}$ ).

The rate increased to the observed potential until $100 \mathrm{mV} / \mathrm{s}$ and levelled off thereafter.

Scan rate studies were then carried out to understand whether the processes on GC electrode were under diffusion or adsorption control. When the scan rate was varied from 5 to $750 \mathrm{mV} / \mathrm{s}$ in $8 \times 10^{-5} \mathrm{M}$ fulvestrant, a linear dependence of the peak intensity $I_{p}(\mu \mathrm{A})$ upon the square root of the scan rate $\left(\nu^{1 / 2}\right)(\mathrm{mV} / \mathrm{s})$ was found, demonstrating a diffusional behavior.

The equation is for GC electrode in $0.1 \mathrm{M} \mathrm{H}_{2} \mathrm{SO}_{4}$ solution

$$
I_{p}(\mu A)=0.31 \nu^{1 / 2}(m V / s)-0.51 ; r=0.997, n=8 .
$$

(SE of intercept: $1.32 \times 10^{-1}$, SEofslope: $1.05 \times 10^{-2}$ )

It followed from the variation of the logarithm of the peak current as a function of the logarithm of the sweep rate in the range of $5-750 \mathrm{mV} / \mathrm{s}$ that the process was diffusion controlled since the value of the straight $\operatorname{line} \log I_{p}=f(\log v)$ was equal to 0.58 . This demonstrated that the process had a diffusive component.

Tafel plot was obtained with a scan rate of $5 \mathrm{mV} / \mathrm{s}$ beginning from a steady-state potential in $0.1 \mathrm{M} \mathrm{H}_{2} \mathrm{SO}_{4}$ from the slope of the linear part. The $\alpha n$ value was 0.33 . The exchange current density $\left(I_{o}\right)$ was $1.76 \times 10^{-10} \mathrm{~A} \mathrm{~cm}^{-2}$ for this system.

The results showed that oxidation of fulvestrant may be postulated by oxidation of the phenolic hydroxyl group. To investigate this founding, comparative studies on levodopa, carbidopa, benserazide, epirubicin, and doxorubicin related for the hydroxyl group of fulvestrant were carried out by $\mathrm{CV}$ on GC electrode as a function of $\mathrm{pH}$ in order to identify the other oxidation step of fulvestrant. The cyclic voltammograms of the compounds closely matched the more positive part of the voltammograms of fulvestrant. It was assumed that the oxidation process, via an initial oxidation of two electrons and the conversion of hydroxyl group to quinone, might be occurring on the selected compounds and the hydroxyl group of fulvestrant, which was electroactive in both acidic and basic media.

\subsection{Analytical Applications and Validation of the Proposed} Method. After the preliminary trials using different percentage of methanol and acetonitrile, 30\% of acetonitrile ratio gave the finest response and solubility. The best result with respect to signal enhancement and peak shape accompanied by sharper response was obtained with $0.1 \mathrm{M}$ sulphuric acid with constant amount acetonitrile as $30 \%$. The calibration graph from the standard solution of fulvestrant according to 


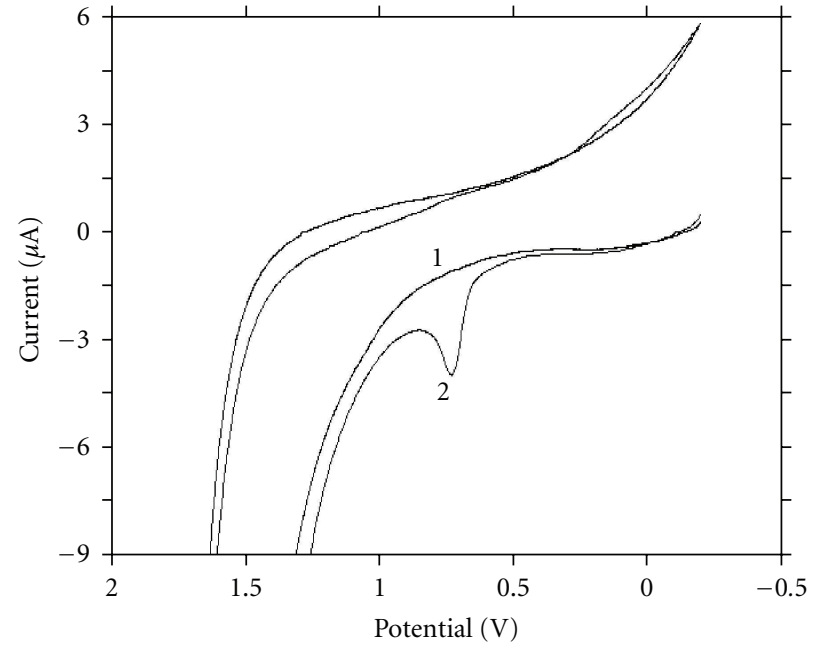

(a)

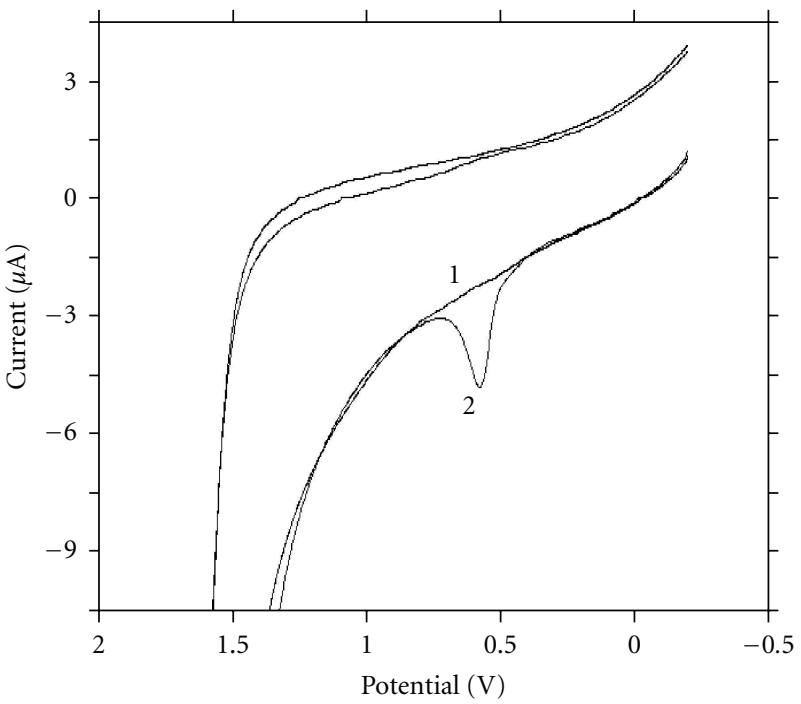

(c)

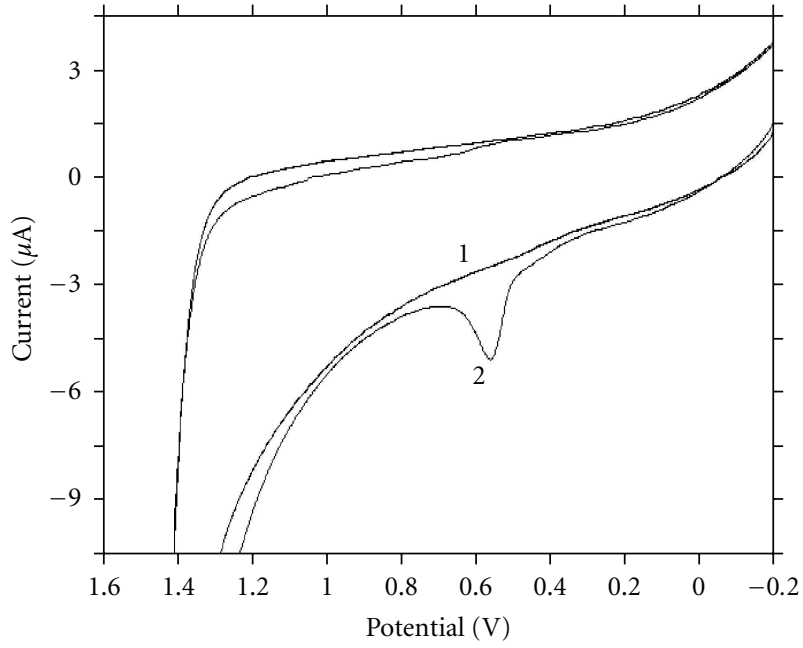

(b)

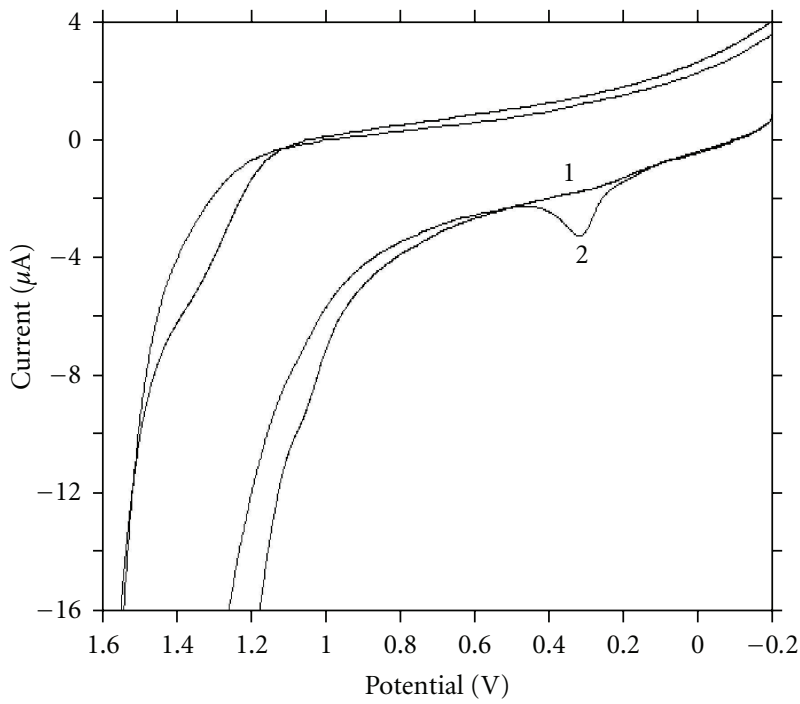

(d)

Figure 2: Cyclic voltammograms of supporting electrolyte (1) and $8 \times 10^{-5} \mathrm{M}$ fulvestrant (2) on GC electrode. (a) pH 2.0 phosphate buffer; (b) $\mathrm{pH} 4.5$ acetate buffer; (c) pH 5.0 BR buffer; (d) pH 9.0 BR buffer solutions.

the procedures described above was constructed by DPV. A linear relation in the concentration range between $4 \times 10^{-6} \mathrm{M}$ and $6 \times 10^{-5} \mathrm{M}$ was found, indicating that the response was diffusion controlled in this range. The characteristics of the calibration plot are summarized in Table 1.

The limit of detection (LOD) and the limit of quantification (LOQ) were calculated on the peak current using the following equations:

$$
\mathrm{LOD}=3.3 \mathrm{~s} / \mathrm{m} ; \quad \mathrm{LOQ}=10 \mathrm{~s} / \mathrm{m},
$$

where $s$ is the standard deviation of the peak currents (three runs), and $\mathrm{m}$ is the slope of the calibration curve. The LOD and LOQ values were also shown is Table 1 .

The low values of SE of slope, the intercept, and a correlation coefficient greater than 0.99 in the supporting electrolyte and human serum samples confirmed the precision of the proposed method.
The stability of the reference substance and sample solutions was checked by analyzing prepared standard solution of fulvestrant in the supporting electrolyte aged at $+4^{\circ} \mathrm{C}$ in the dark against freshly prepared sample. The results demonstrated that the working reference solutions were stable at least for 3 days. The fulvestrant response for the assay reference solutions did not change considerably over 3 days.

The developed techniques were validated according to the ICH guidelines [21]. The results are summarized in Table 1. Accuracy, precision, specificity, selectivity, reproducibility, LOD, and LOQ of the proposed techniques were assessed by performing replicate analysis of the standard solutions in the supporting electrolyte and human serum samples within calibration curves. The selected concentrations were prepared in both media, assayed with the related calibration equations to determine repeatability and 


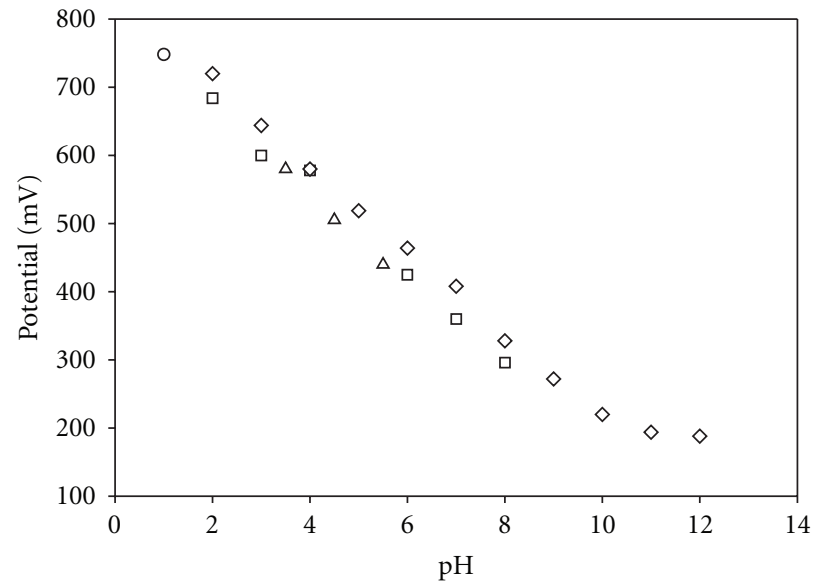

(a)

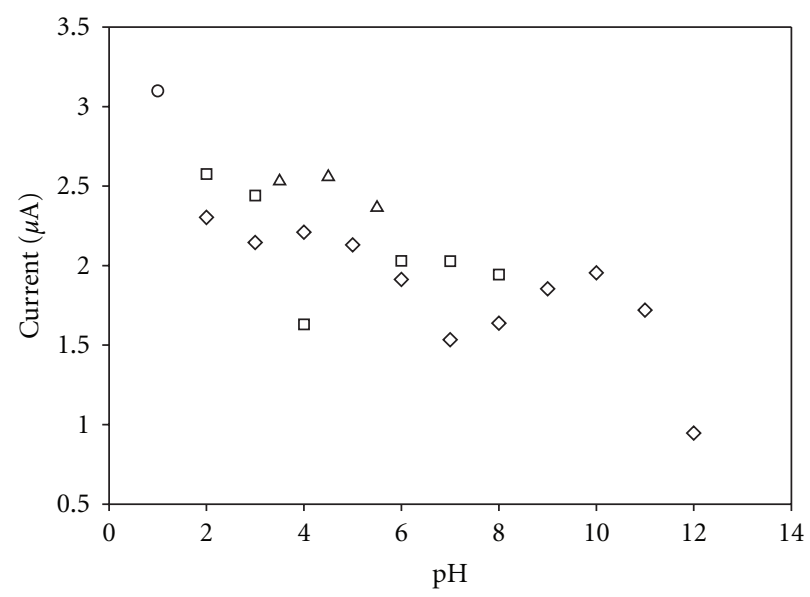

(b)

FIGURE 3: Effect of $\mathrm{pH}$ on fulvestrant anodic peak potential (a) and peak current (b); fulvestrant concentration: $8 \times 10^{-5} \mathrm{M}$. $(\bigcirc) 0.1 \mathrm{M}$ sulphuric acid; $(\square) 0.2 \mathrm{M}$ phosphate; $(\triangle) 0.2 \mathrm{M}$ acetate; $(\diamond) 0.04 \mathrm{M}$ BR buffers.

TABLE 1: Regression data of the calibration curve and quantitative determination of fulvestrant by DPV in standard solution and human serum.

\begin{tabular}{lcc}
\hline & Standard solution & Serum \\
\hline Measured potential $(\mathrm{V})$ & 0.83 & 0.84 \\
Linearity range $(\mathrm{M})$ & $4 \times 10^{-6}-6 \times 10^{-5}$ & $2 \times 10^{-5}-1 \times 10^{-4}$ \\
Slope $\left(\mu \mathrm{A} \mathrm{M}^{-1}\right)$ & $5.34 \times 10^{4}$ & $8.21 \times 10^{3}$ \\
Intercept $(\mu \mathrm{A})$ & $2.78 \times 10^{-2}$ & $-5.22 \times 10^{-2}$ \\
Correlation coefficient & 0.998 & 0.999 \\
SE of slope & $1.60 \times 10^{3}$ & $7.06 \times 10^{2}$ \\
SE of intercept & $4.61 \times 10^{-2}$ & $1.00 \times 10^{-3}$ \\
LOD $(\mathrm{M})$ & $5.40 \times 10^{-7}$ & $5.07 \times 10^{-6}$ \\
LOQ $(\mathrm{M})$ & $1.80 \times 10^{-6}$ & 0.51 \\
Repeatability of peak current (RSD\%) & 0.93 & 0.26 \\
Repeatability of peak potential (RSD\%) & 0.26 & 0.72 \\
Reproducibility of peak current (RSD\%) & 1.68 & 0.32 \\
Reproducibility of peak potential (RSD\%) & 0.26 & \\
\hline
\end{tabular}

reproducibility, and were shown as $\mathrm{RSD} \%$ values in Table 1. The validation results shown in Table 1 demonstrate good precision, accuracy, and reproducibility.

\subsection{Determination of Fulvestrant in Injectable Dosage Forms.}

On the basis of above results, DPV method was applied to the direct determination of fulvestrant in injectable dosage forms, using related calibration straight line without any sample extraction, evaporation, or filtration other than an adequate dilution step. The mean results were found very close to the confirmed value of $250 \mathrm{mg} / 5 \mathrm{~mL}$. The results showed that the proposed method was successfully applied for the assay of fulvestrant in its dosage forms (Table 2). There is no official method present in any pharmacopoeias (e.g., USP, BP, or EP) related to pharmaceutical dosage forms or bulk drugs of fulvestrant. For checking the accuracy, precision, and selectivity of the proposed methods and in order to know whether the excipients in pharmaceutical dosage forms show any interference with the analysis,
TABLE 2: Results obtained from the determination and recovery experiments in injectable dosage form.

\begin{tabular}{lc}
\hline Labeled claim $\left(\mathrm{mg} 5 \mathrm{~mL}^{-1}\right)$ & 250.00 \\
\hline Amount found $^{\mathrm{a}}$ & 262.96 \\
RSD\% & 0.70 \\
Bias\% & -5.18 \\
Added fulvestrant $(\mathrm{mg})$ & 20.00 \\
Found fulvestrant $(\mathrm{mg})^{\mathrm{a}}$ & 19.90 \\
Average recovery\% & 99.49 \\
RSD\% of recovery & 0.53 \\
Bias\% & 0.51 \\
\hline
\end{tabular}

${ }^{a}$ Each value means five experiments.

the proposed methods were evaluated by recovery tests after addition of known amounts of pure drug to various preanalyzed formulation of fulvestrant. 
TABLE 3: Results obtained from fulvestrant determination from spiked serum.

\begin{tabular}{lc}
\hline Added fulvestrant concentration $(\mathrm{M})$ & $8.00 \times 10^{-5}$ \\
\hline Obtained fulvestrant concentration $(\mathrm{M})$ & $7.60 \times 10^{-5}$ \\
Number of experiments & 5 \\
Average recovery\% & 94.87 \\
RSD\% of recovery & 1.56 \\
Bias\% & 5.13 \\
\hline
\end{tabular}

In order to detect interactions of excipients, the standard addition technique was applied to the same pharmaceutical preparations, which were analyzed by the calibration curve. Recovery experiments using the developed assay procedures further indicated the absence of interference from commonly encountered pharmaceutical excipients used in the selected formulations (Table 2). The results indicated the validity of the proposed techniques for the determination of fulvestrant in injectable dosage form (Table 2).

\subsection{Determination of Fulvestrant in Spiked Human Serum.} The optimized procedure was successfully applied to the determination of fulvestrant in protein-free spiked human samples. Acetonitrile was used as a serum precipitating agent. The best results were obtained with $5.4 \mathrm{~mL}$ of acetonitrile. No extraction or evaporation other than the centrifugal protein separation was required prior to assay for the drug. The measurements of fulvestrant in serum samples were performed as described in Section 2.

The applicability of the proposed method to the human serum samples and the calibration equation were obtained in spiked human serum samples. Calibration equation parameters and essential validation data were shown in Table 1 . The recovery results of fulvestrant in serum samples were calculated from the related linear regression equation, which were given in Table 1 . Recovery results of spiked human serum samples were given in Table 3.

Analysis of drugs from serum samples usually requires extensive time-consuming sample preparation and use of expensive organic solvents and other chemicals. In this study, the serum proteins and endogenous substances in serum samples were precipitated by the addition of acetonitrile and centrifugation at $5000 \mathrm{rpm}$. The supernatant was taken and diluted with the supporting electrolyte and directly analyzed. Typical DPV curves of fulvestrant examined in serum samples were shown in Figure 4. There were no oxidation compounds and no extra noise peaks presented in biological material peak occurred in the potential range where the analytical peak appeared.

Stability of serum samples kept in cold $\left(+4^{\circ} \mathrm{C}\right)$ was tested with five consecutive analyses of the sample over a period of approximately $5 \mathrm{~h}$. There were no significant changes in the peak currents and potentials between the first and last measurements.

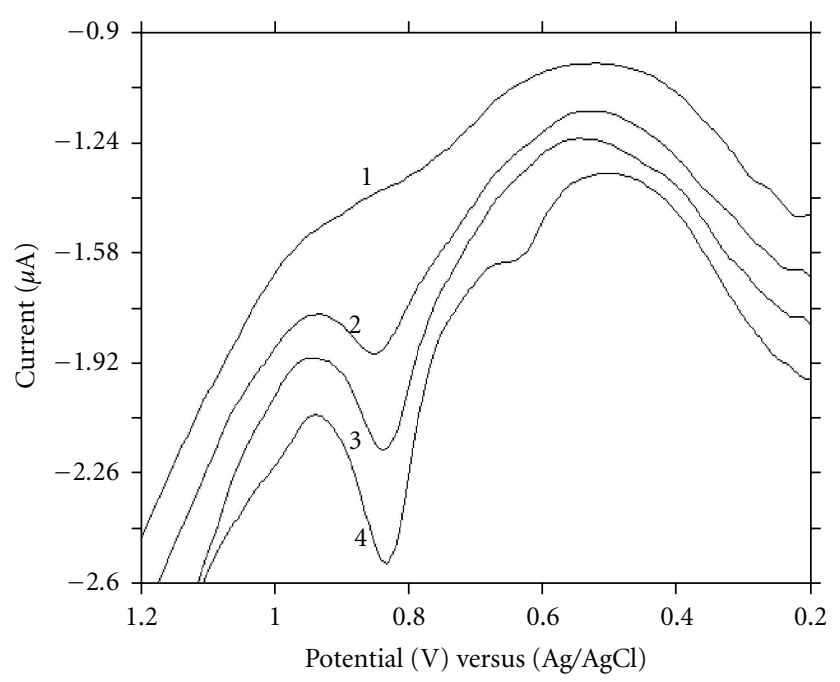

FIgURE 4: DP voltammograms in $0.1 \mathrm{M}$ sulphuric acid for the determination of fulvestrant in spiked human serum samples: (1) blank serum extract, (2) extract containing $4 \times 10^{-5} \mathrm{M}$, (3) extract containing $6 \times 10^{-5} \mathrm{M}$, and (4) extract containing $1 \times 10^{-4} \mathrm{M}$.

\section{Conclusion}

The electrochemical behavior of fulvestrant was examined for the first time with this study. The voltammetric oxidation steps of fulvestrant in different buffer solutions of $\mathrm{pH} 0.3-$ 12.0 have been elucidated with glassy carbon electrode. The detailed electrooxidation outcome of fulvestrant at carbonbased electrodes might be used for analytical purposes, particularly as a sensor.

Fully validated, highly selective and sensitive, simple and precise voltammetric procedures were described for determination of fulvestrant in bulk form, pharmaceutical dosage form, and human serum samples without the necessity of sample pretreatment or time-consuming extraction and evaporation steps prior to the analysis.

In this study, possible oxidation pathways were investigated to identify the functional groups responsible from the oxidation. Therefore, the oxidation process of fulvestrant was compared with some model compounds. Comparative studies on levodopa, carbidopa, benserazide, epirubicin, and doxorubicin related for the hydroxyl group of fulvestrant were performed by $\mathrm{CV}$ on BDD electrode, as a function of $\mathrm{pH}$, in order to identify the oxidation step of fulvestrant. The oxidation mechanism of fulvestrant found related to the oxidation of the hydroxyl group on the aromatic ring.

Consequently, the above-presented technique is a good analytical alternative for determining fulvestrant in pharmaceutical dosage forms and spiked serum samples. This study only shows the possibility of monitoring this compound that makes the method useful for pharmacokinetic and pharmacodynamic purposes. However, the proposed methods might be alternatives to the HPLC techniques in therapeutic drug monitoring, or the experimental data might be used for the development of HPLC-EC method. 


\section{Acknowledgments}

This work is produced from Ph.D. thesis of Pharm. Burcu Dogan-Topal (Ankara University, Health Science Institute). This research was supported by a Grant from Ankara University Scientific Project Foundation (Grant no. 20030803043) for Dr. B. Uslu. The authors would like to thank Asta Zeneca (Istanbul, Turkey) for providing standard fulvestrant and pharmaceutical dosage forms for developing the proposed method.

\section{References}

[1] http://www.cancer.org/Treatment/TreatmentsandSideEffects/ index.

[2] http://en.Wikipedia.org/wiki/Fulvestrant.

[3] I. Vergote and P. Abram, "Fulvestrant, a new treatment option for advanced breast cancer: tolerability versus existing agents," Annals of Oncology, vol. 17, no. 2, pp. 200-204, 2006.

[4] D. Dodwell and I. Vergote, "A comparison of fulvestrant and the third-generation aromatase inhibitors in the second-line treatment of postmenopausal women with advanced breast cancer," Cancer Treatment Reviews, vol. 31, no. 4, pp. 274-282, 2005.

[5] Physicians Desk Reference (PDR), Published by Thomson PDR, Montvale, p. 653, 2005.

[6] D. Dodwell, G. Coombes, J. M. Bliss, L. S. Kilburn, and S. Johnston, "Combining fulvestrant (Faslodex ${ }^{\mathrm{TM}}$ ) with continued oestrogen suppression in endocrine-sensitive advanced breast cancer: the SoFEA trial," Clinical Oncology, vol. 20, no. 5, pp. 321-324, 2008.

[7] J. Wang, Electroanalytical Techniques in Clinical Chemistry and Laboratory Medicine, VCH, New York, NY, USA, 1988.

[8] P. T. Kissenger and W. R. Heineman, Laboratory Techniques in Electroanalytical Chemistry, Marcel Dekker, New York, NY, USA, 2nd edition, 1996.

[9] D. K. Gosser, Ed., Cyclic Voltammetry, Simulation and Analyssis of Reaction Mechanism, VCH, New York, NY, USA, 1993.

[10] S. A. Özkan, B. Uslu, and H. Y. Aboul-Enein, "Analysis of pharmaceuticals and biological fluids using modern electroanalytical techniques," Critical Reviews in Analytical Chemistry, vol. 33, no. 3, pp. 155-181, 2003.

[11] B. Uslu and S. A. Ozkan, "Solid electrodes in electroanalytical chemistry: present applications and prospects for high throughput screening of drug compounds," Combinatorial Chemistry and High Throughput Screening, vol. 10, no. 7, pp. 495-513, 2007.

[12] B. Uslu and S. A. Ozkan, "Electroanalytical application of carbon based electrodes to the pharmaceuticals," Analytical Letters, vol. 40, no. 5, pp. 817-853, 2007.

[13] C. M. Riley and T. W. Rosanske, Development and Validation of Analytical Methods, Elsevier Science, New York, NY, USA, 1996.

[14] M. E. Swartz and I. S. Krull, Analytical Method Development and Validation, Marcell Dekker, New York, NY, USA, 1997.

[15] J. Ermer and J. H. Miller, Eds., Method Validation in Pharmaceutical Analysis, Wiley-VCH, Veinheim, Germany, 2005.

[16] P. Bievre and H. Günzler, Validation in Chemical Measurements, Springer, New York, NY, USA, 2005.

[17] E. R. Brown, R. F. Large, A. Weissberger, and B. W. Rossiter, Eds., Physical Methods of Chemistry, Wiley Insterscience, Rochester, NY, USA, 1964.
[18] R. N. Goyal, V. K. Gupta, M. Oyama, and N. Bachheti, "Differential pulse voltammetric determination of atenolol in pharmaceutical formulations and urine using nanogold modified indium tin oxide electrode," Electrochemistry Communications, vol. 8, no. 1, pp. 65-70, 2006.

[19] R. N. Goyal, N. Jain, and V. Gurnani, "Electrooxidation of chlorpromazine in aqueous and micellar media and spectroscopic studies of the derived cationic free radical and dication species," Monatshefte für Chemie, vol. 132, no. 5, pp. 575-585, 2001.

[20] SciFinder Scholar Programme, American Chemical Society, Vesion, 2007.

[21] Expert Working Group (Quality) of the ICH, "ICH-Q2Bnvalidations of analytical procedures: methodology," in International Conference on Harmonization of Technical Requirements for Registration of Pharmaceuticals for Human Use, Geneva, Switzerland, November 1996. 


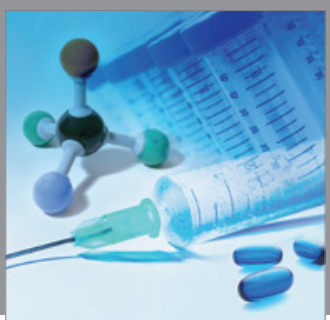

International Journal of

Medicinal Chemistry

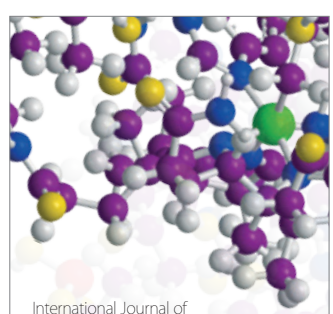

Carbohydrate Chemistry

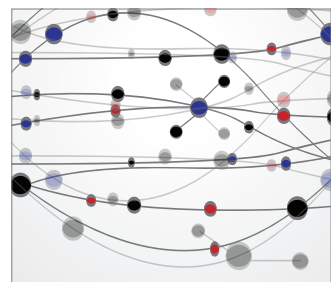

The Scientific World Journal
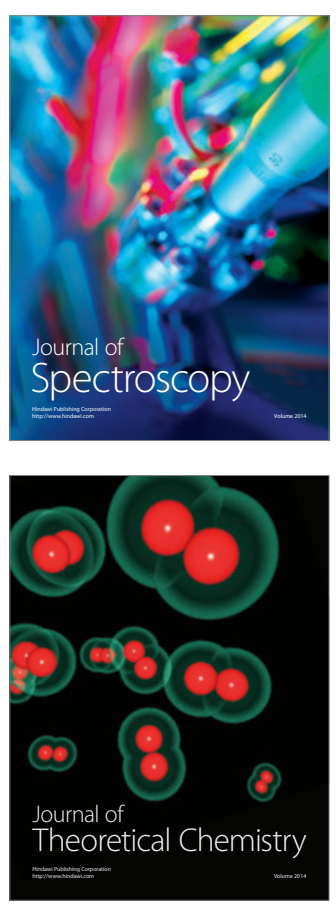
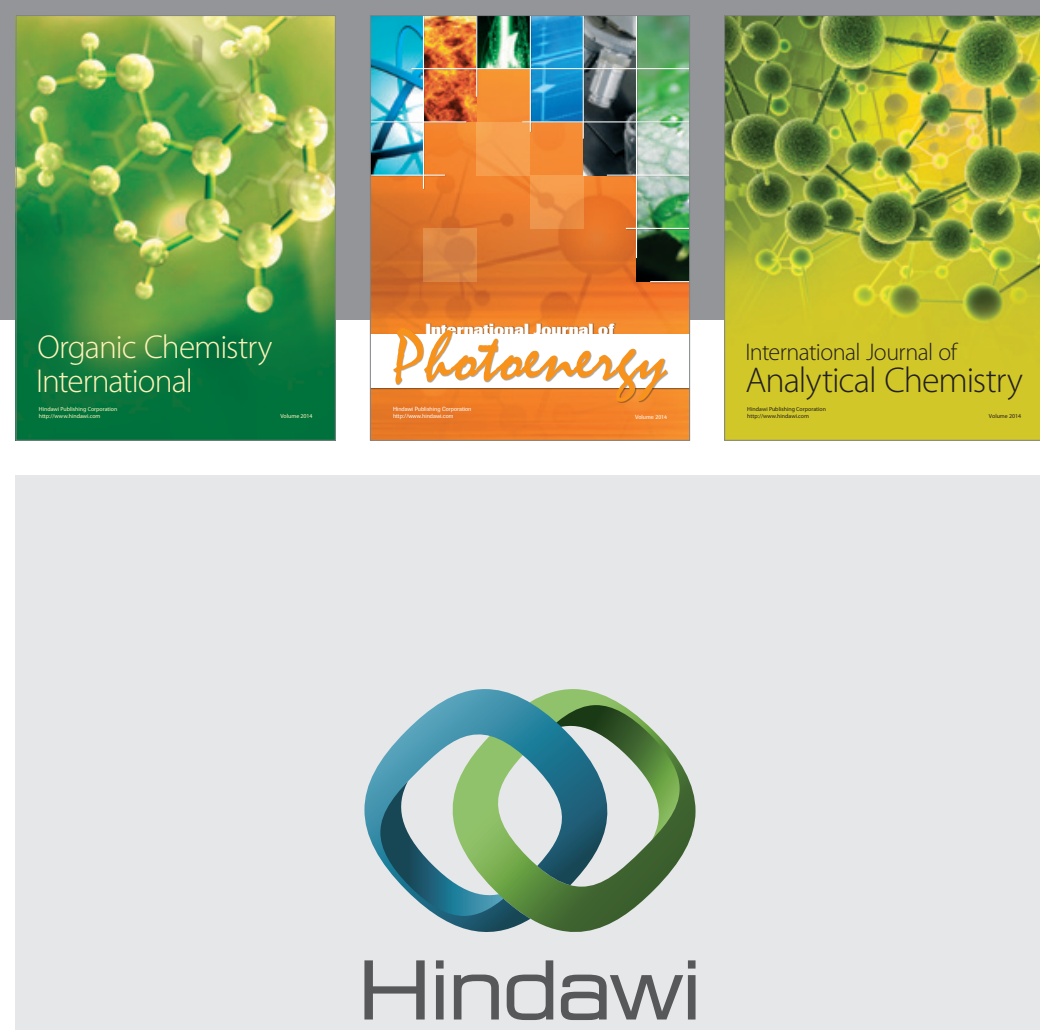

Submit your manuscripts at

http://www.hindawi.com
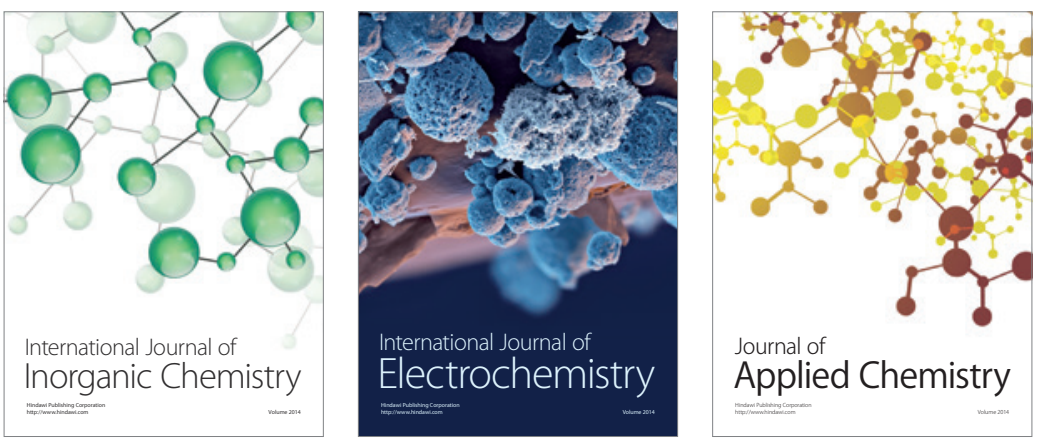

Journal of

Applied Chemistry
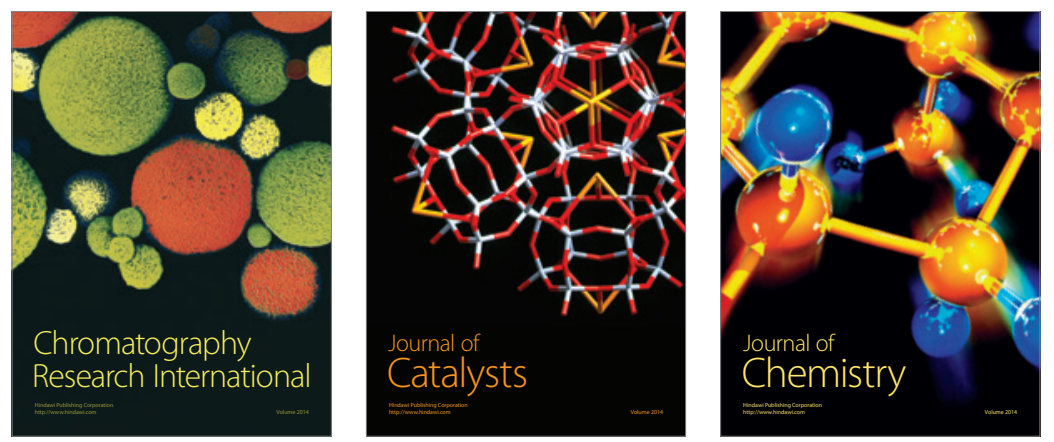
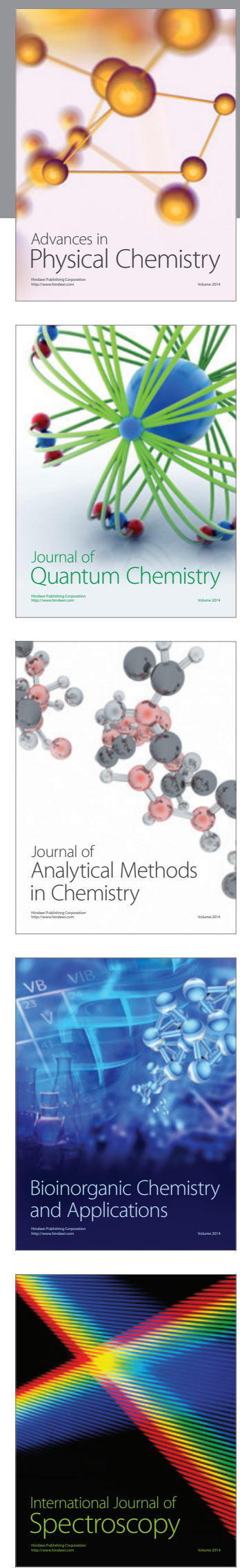